Sanofi-Regeneron, Speakers bureau: AbbVie, Aesku, Alfa-Wassermann, Bristol-Myers Squibb, Biogen, Celgene, Eli-Lilly, Grifols, Janssen, MSD, Novartis, Pfizer, Roche, Sanofi-Genzyme, UCB Pharma, Rosa Daniela Grembiale: None declared, Roberta Ramonda Speakers bureau: Novartis, Celgene, Janssen, Pfizer, Abbvie, Lilly, Lorenzo Dagna Grant/research support from: Abbvie, BMS, Celgene, Janssen, MSD, Mundipharma Pharmaceuticals, Novartis, Pfizer, Roche, SG, SOBI, Consultant of: Abbvie, Amgen, Biogen, BMS, Celltrion, Novartis, Pfizer, Roche, SG, and SOBI, Salvatore D’Angelo Speakers bureau: AbbVie, Biogen, BMS, Celgene, Janssen, Lilly, MSD, Novartis, Pfizer, Sanofi, and UCB, Roberto Gerli: None declared, Salvatore De Vita Consultant of: Roche, Human Genome Science, Glaxo Smith Kline and Novartis, Silvia Marelli Employee of: Janssen, Daniela Frigerio Employee of: Janssen, Ennio Favalli Speakers bureau: BMS, Eli-Lilly, MSD, UCB, Pfizer, Sanofi-Genzyme, Novartis and Abbvie DOI: 10.1136/annrheumdis-2020-eular.2876

\section{AB0681 COMPARISON BETWEEN DEMOGRAPHIC AND CLINICAL CHARACTERISTICS OF PREDOMINANT AXIAL VS MAINLY PERIPHERAL SPONDYLOARTHRITIS (SPA) PATIENTS, ENROLLED IN THE ONGOING SIRENA STUDY}

R. Foti ${ }^{1}$, G. Cardinale ${ }^{2}$, L. Costa ${ }^{3}$, F. Franceschini ${ }^{4}$, F. Ciccia ${ }^{5}$, A. Marchesoni ${ }^{6}$, G. Guggino ${ }^{7}, M$. Rossini ${ }^{8}$, E. Lubrano ${ }^{9}$, M. Galeazzi ${ }^{10}$, M. Chimenti $i^{11}$ G. Bianchi ${ }^{12}$, G. Galfo ${ }^{13}$, S. Marelli ${ }^{14}$, E. Favallii ${ }^{15}$ on behalf of the SIRENA Study Group. ${ }^{1}$ U.O. Reumatologia, AOU Policlinico Vittorio Emanuele, Catania, Italy; ${ }^{2}$ U.O. Reumatologia, Distretto nr. 1 ULSS6 Euganea, Padova, Italy; ${ }^{3}$ U.O.C. Reumatologia, Università degli Studi Federico II, Napoli, Italy; ${ }^{4}$ U.O.C. Reumatologia e Immunologia Clinica, ASST Spedali Civili, Brescia, Italy; ${ }^{5}$ Università della Campania Luigi Vanvitelli, Napoli, Italy; ${ }^{6}$ S. C. Day Hospital Reumatologia, ASST Gaetano Pini e CTO, Milano, Italy; ${ }^{7}$ U.O. Reumatologia, AOU Policlinico Paolo Giaccone, Palermo, Italy; ${ }^{8}$ U.O.C. Reumatologia, Ospedale Policlinico Borgo Roma, Verona, Italy; ${ }^{9}$ U.O.S.V.D. Reumatologia, Università degli Studi del Molise, Campobasso, Italy; ${ }^{10}$ U.O.C. Reumatologia, AOU Senese, Siena, Italy; ${ }^{11}$ Reumatologia, Allergologia e Immunologia Clinica, Università Tor Vergata, Roma, Italy; ${ }^{12}$ S. C. Reumatologia, ASL3, Genova, Italy; ${ }^{13}$ U. O. Reumatologia e Medicina Generale, Ospedale Busacca, Scicli (RG), Italy; ${ }^{14}$ Janssen, MAF Immunology, Cologno Monzese (MI), Italy; ${ }^{15}$ S.C. Reumatologia, ASST Gaetano Pini e CTO, Milano, Italy

Background: SIRENA is an Italian, prospective Registry in Spondyloarthritis (SpA) patients, naïve to conventional, targeted and biological DMARDs. Patients are diagnosed, newly or confirmed, according to ASAS criteria and classified in subjects with predominant axial (AX) or with mainly peripheral manifestations (PER).

Objectives: To compare descriptively AX vs PER subgroups of patients.

Methods: Demographic data, diagnostic delay and subtypes of $\mathrm{SpA}$ as well as clinical features and comorbidities are collected.

Results: 282 patients were enrolled: 101 (35.8\%) AX and 181 (64.2\%) PER. Baseline data are shown in Table 1. There were more obese patients in $A X$ (21.4\% AX vs $16.1 \%$ PER) and more overweight ones in PER $(19.4 \%$ AX vs $23.8 \% \mathrm{PER})$. The $\%$ of subjects with diagnostic delay was higher in AX $(65.7 \%$ vs $53.9 \%$ PER) and the delay longer (mean of 73.1 months vs 47.8 ). In both groups, main reason of the delay was incorrect referrals ( $41.5 \%$ for AX and $45.3 \%$ for PER). Noteworthy the fact that in PER, the $75.7 \%$ of patients had a newly diagnosed SpA. In PER, the most frequent SpA type was PsA (82.3\%), followed by undifferentiated $\mathrm{SpA}(8.8 \%)$ and enteropathic SpA $(7.5 \%)$, while in $\mathrm{AX}, 49.5 \%$ were ankylosing spondylitis, $21.8 \%$ nr-ax-SpA and only $4 \%$ PsA. The majority of PER patients reported as first symptom peripheral arthritis (80/181), psoriasis $(57 / 181)$ and enthesitis while in AX referred inflammatory back pain (80/101). High percentages of comorbidities were reported: psoriasis $(65.8 \%)$ and cardiometabolic diseases (34.8\%) were higher in PER while depression/anxiety and GI diseases were higher in AX (Table 2). At the baseline, the mean PhGA score (0-100) was 51.5 for AX and 43.8 for PER.

Conclusion: SIRENA study highlights relevant differences in AX vs PER patients, expecially in terms of diagnostic delay, clinical presentation and comorbidities.

Table 1.

\begin{tabular}{lcc}
\hline & $\begin{array}{c}\text { Mean } \\
\text { AX } \mathbf{n = 1 0 1}\end{array}$ & $\begin{array}{c}\text { Mean } \\
\text { PER } \mathbf{n = 1 8 1}\end{array}$ \\
\hline Age (years) & 47.3 & 52.8 \\
Sex (female/male - \%) & $50.5 / 49.5$ & $47.5 / 52.5$ \\
Weight (Kg) & 73.0 & 73.9 \\
BMl & 25.3 & 25.4 \\
Diagnostic Delay (yes - \%) & $65.7 \%$ & $53.9 \%$ \\
Time of delay (mean - months) & 71.3 & 47.8 \\
Newly SpA diagnosis (\%) & $55.5 \%$ & $75.7 \%$ \\
\hline
\end{tabular}

Table 2.

\begin{tabular}{lcc}
\hline $\begin{array}{l}\text { A) First Symptom } \\
\text { (more than 1 symptom referred) }\end{array}$ & $\begin{array}{c}\text { AX } \mathbf{n}=\mathbf{1 0 1} \\
\text { N. Patients }\end{array}$ & $\begin{array}{c}\text { PER } \mathbf{n = 1 8 1} \\
\text { N. Patients }\end{array}$ \\
\hline Arthritis & 23 & 122 \\
Enthesitis & 16 & 54 \\
Dactylitis & 7 & 28 \\
Inflammatory Back Pain & 80 & 34 \\
Psoriasis skin & 10 & 57 \\
Psoriasis nails & 2 & 19 \\
Uveitis & 4 & 1 \\
IBD & 7 & 9 \\
B) Comorbidities & $\%$ Patients & $\%$ Patients \\
(more than 1 comorbidity referred) & & \\
Cardiometabolic & $20.8 \%$ & $34.8 \%$ \\
-Hypertension & $19.8 \%$ & $30.9 \%$ \\
-Dyslipidemia & $17.8 \%$ & $11.6 \%$ \\
-Diabetes & $6.0 \%$ & $7.7 \%$ \\
-MetS & $5.0 \%$ & $6.6 \%$ \\
Psoriasis & $22.8 \%$ & $65.8 \%$ \\
Gastrointestinal & $20.8(16.9 \% \mathrm{CD})$ & $12.8(4.4 \% \mathrm{CD})$ \\
Depression/Anxiety & $11.9 \%$ & $2.2 \%$ \\
Endocrine & $6.9 \%$ & $11.1 \%$ \\
Osteoporosis & $3 \%$ & $5.5 \%$ \\
Hepatic & $4 \%(3 \% \mathrm{NAFLD})$ & $4.4 \%(2.2 \%$ NAFLD) \\
Infections & $3 \%$ & $3.9 \%$ \\
Malignancies & $0 \%$ & $4.4 \%$ \\
\end{tabular}

Acknowledgments: This study was sponsored by Janssen Italy. We thank the Investigators and their staff at all of the study sites.

Disclosure of Interests: Rosario Foti Speakers bureau: Abbvie, BMS, ROCHE, Janssen, Celgene, Gabriella Cardinale: None declared, Luisa Costa: None declared, Franco Franceschini Consultant of: Eli-Lilly, Janssen, Pfizer, Sanofi-Genzyme, UCB Pharma, GSK, Francesco Ciccia Grant/ research support from: Pfizer, Novartis, Celgene, Janssen, Consultant of: Lilly, Novartis, Pfizer, Janssen, Roche, Celgene, Speakers bureau: Pfizer, Novartis, Celgene, Janssen, Roche, Abiogen, BMS, Antonio Marchesoni Speakers bureau: Abbvie, Pfizer, UCB, Novartis, Celgene, Eli Lilly, Giuliana Guggino Grant/research support from: Pfizer, Celgene, Speakers bureau: Celgene, Sandoz, Pfizer, Maurizio Rossini Speakers bureau: AbbVie, Abiogen, Amgen, BMS, Eli-Lilly, Novartis, Pfizer, Sanofi, Sandoz and UCB, Ennio Lubrano: None declared, Mauro Galeazzi: None declared, Mariasole Chimenti: None declared, Gerolamo Bianchi Grant/research support from: Celgene, Consultant of: Amgen, Janssen, Merck Sharp \& Dohme, Novartis, UCB, Speakers bureau: Abbvie, Abiogen, Alfa-Sigma, Amgen, BMS, Celgene, Chiesi, Eli Lilly, GSK, Janssen, Medac, Merck Sharp \& Dohme, Novartis, Pfizer, Roche, Sanofi Genzyme, Servier, UCB, Giuseppe Galfo: None declared, Silvia Marelli Employee of: Janssen, Ennio Favalli Speakers bureau: BMS, Eli-Lilly, MSD, UCB, Pfizer, Sanofi-Genzyme, Novartis and Abbvie

DOI: 10.1136/annrheumdis-2020-eular.1066

\section{\begin{tabular}{|l|l}
\hline AB0682 & FUNCTIONAL IMPAIRMENT IN PATIENTS WITH AXIAL
\end{tabular} SPONDYLOARTHROPATHY IN A GERMAN COHORT: WORSE OUTCOMES AND WORSE QUALITY OF LIFE FOR FEMALE PATIENTS}

N. Frede ${ }^{1}$, S. Hiestand ${ }^{1}$, S. Finzel ${ }^{1}$, R. Voll ${ }^{1}$, J. Thiel ${ }^{1}$, N. Venhoff ${ }^{1}{ }^{1}{ }^{M e d i c a l}$ Center - University of Freiburg, Faculty of Medicine, University of Freiburg, Department of Rheumatology and Clinical Immunology, Freiburg im Breisgau, Germany

Background: Axial spondyloarthritis (AxSpA) may lead to significant structural damage resulting in marked impairment and disability. Historically, AxSpA has been thought to have a distinct male predominance regarding both, occurrence but also disease severity. However, it has recently been shown in international cohorts that women with AxSpA may have in fact an increased disease burden and worse outcome than their male counterparts.

Objectives: The aim of this project was to analyse functional capacity in a German cohort of AxSpA patients and identify associated factors by comparing demographic data, clinical characteristics, disease activity and treatments.

Methods: Analysis of a German University Hospital outpatient clinic cohort of 150 AxSpA patients. Questionnaire-based screening tools were used to assess disease activity, functional impairment and quality of life (BASDAl, FFbH, WHOQOL-BREF). Female and male patients were compared by independent samples two-tailed $T$ tests for continuous variables as well as chi-squared test for categorical variables. 